Article

\title{
Comparative Analysis on Environmental Adaptability of Two Types of Bank Stabilization Structures along the Middle and Lower Reaches of the Yangtze River
}

\author{
Yujie Fan ${ }^{1}$, Zhonghua Yang ${ }^{1, *}$, Ming $\mathrm{Li}^{2}$, Zhiyong Zhang ${ }^{3}$ and $\mathrm{Da} \mathrm{Li}^{1}{ }^{1}$ \\ 1 State Key Laboratory of Water Resources and Hydropower Engineering Science, Wuhan University, \\ Wuhan 430072, China; 2019282060127@whu.edu.cn (Y.F.); whulida@whu.edu.cn (D.L.) \\ 2 Changjiang Waterway Institute of Planning and Design, Wuhan 430040, China; cjhdyjy@163.com \\ 3 Institute of Hydroecolog, Ministry of Water Resources, Chinese Academy of Sciences, Wuhan 430079, China; \\ zhanzy@mail.ihe.ac.cn \\ * Correspondence: yzh@whu.edu.cn
}

Received: 22 August 2020; Accepted: 24 September 2020; Published: 27 September 2020 updates

\begin{abstract}
With the aim to prevent channel incision and migration and provide protection at the riverbank, a series of ecological bank stabilization projects have been carried out in the middle and lower reaches of the Yangtze River. In this study, nine ecological bank stabilization areas using two different techniques, Steel mesh gabion (Type 1) and Chain-type bricks (Type 2), were compared in terms of environmental adaptability on the basis of the survey data of vegetation and substrate. There were no significant differences between the two types of dominant species before and after the flood season. Annual or biennial herbaceous plants had clear spatial competitive advantages while perennial herbs had clear temporal competitive advantages. While Type 1 was better than Type 2 in overall vegetation restoration and growth, Type 2 was more sensitive to periodic flood disturbance. Redundancy Analysis was used to determine the main environmental impact factors that caused differences on biotic indices of the two types. The clay content in the substrate was an important factor affecting vegetation cover and diversity for Type 1 while the substrate nutrient composition was important for Type 2. Generally, Type 1 presented stronger environmental adaptability in channel regulation projects.
\end{abstract}

Keywords: bank stabilization structures; vegetation restoration; biotic indices; environmental impact factors

\section{Introduction}

The riparian zone is an important transition between the river and terrestrial ecosystems [1]. This zone has severe river erosion and frequent flow and exchange of material, energy, and information [2-4]. Therefore, the riparian zone has become a key research area in channel regulation at home and abroad [5]. With the aim to adjust the flow and stabilize the shoreline, a series of revetment structure projects have been carried out in the middle and lower reaches of the Yangtze River in recent years, with a focus on preventing bed-shape evolution, river-width adjustment, and lateral channel migration. The study of revetment structure not only meets the requirements of flood control and drainage and riverbank stability, but also has important practical significance for maintaining river regime stability, thus improving the river biodiversity, ecosystem productivity, and self-purification capacity [6]. Traditional revetment structures are generally constructed with stone, steel, concrete, and other materials; the main design considerations are the mechanical factors to ensure the stability and economic benefits of traditional slope protection [7]. Blocking the exchange of material and energy between river and land ecosystems leads to the closure of the entire bank slope, which causes 
the riverbank to lose its ecological function and self-purification ability, destroy the diversity of the original river channel, and other adverse effects that hinder the development of traditional revetment structure $[8,9]$.

In the 1970s, the new environmental problems caused by the traditional revetment structure applications attracted the attention of the American public [7]. Biotechnical engineering gained increasing interest, and its benefits and advantages were gradually re-examined. Japan amended the Rivers Law in 1997, which clearly expand the traditional roles of flood control and water supply in river management to include improvement and conservation of rivers and the riparian environment [10]. Schiechtl and Stern (1997) defined woody planting and combined applications of planting and artificial structures as bank stabilization, distinguished from bank protection. Ecological bank stabilization can enable the natural restoration for the bank slope under the premise of satisfying the riverbank stability. Meanwhile, the bioroenosis on riverbanks provides underground soil reinforcement and surface protection from erosion. Biotechnical applications are thus proven as suitable alternatives to traditional practices [7].

For the Yangtze River, due to the large velocity and discharge and the great seasonal variation of water level, before the installation of the new stabilization structures construct, some unprotected river sections were seriously eroded by the river, with little vegetation coverage; the construction of ecological bank stabilization under such complex flow conditions is of great significance. So, people are constantly innovating and researching optimized structures to fully integrate the bank stabilization projects with nature and maximize its ecological benefits. Scientific studies on bioengineering structures along rivers mainly focus on methodological aspects, such as structural optimization and construction methods [11]. Some researchers found that succession of biocenose is found correlated with the techniques used in bank stabilization construction by biological investigation data from different structures [12-14]. The relationship between the distribution and diversity of plant communities and substrates are examined, but mostly concentrated on highway slopes and fluctuations of reservoir water levels [15-20]. Research remains limited on the ecological restoration and the relationship between environmental impact factors and the effect of biological restoration after the construction of different ecological structures on riverbank areas. However, the seasonal water level changes experienced by vegetation in bank stabilization areas are opposite to that in reservoir water-level fluctuations, because during the flood season, the latter is exposed while the former is submerged. For the ecological bank stabilization projects, limited professional data are available to allow tracing and comparison of the comprehensive benefits $[15,16]$.

After the preliminary investigation of ecological bank stabilization in this reach, the ecological bank stabilization projects in the middle and lower reaches of the Yangtze River use mainly two types, steel wire mesh gabions and chain-type bricks. It is found that the application of Type 1 is more widely used than Type 2 because construction of Type 1 is simple and convenient. Meanwhile, it is filled with natural stone and its quality is easy to control and the cost is low. The slope surface was pretreated and the surface substrate of the slope was cleared during construction. However, after the construction of these two types of projects, systematic studies are rarely carried out to compare and evaluate the effect of vegetation restoration despite its ecological significance. This study is based on the survey data of the vegetation and substrate of the two bank stabilization structures before and after the flood season in 2019. According to the difference of vegetation characteristics of sampling points before and after flood season and in different elevation areas, the vegetation restoration situation of the two types is compared, and the difference of environmental impact factors affecting the vegetation characteristics of two types is discussed. On this basis, the environmental adaptability of the two type is comprehensively evaluated. 


\section{Materials and Methods}

\subsection{Sites and Basic Information of Sampling Points}

In this study, combined with design data of these riverbank areas, we selected 9 ecological bank stabilization areas along the Yichang-Anqing of the middle and lower reaches of the Yangtze River (Figure 1a,b). These areas are located in the typical subtropical humid monsoon climate zone. The rainy season begins from June to August every year. The annual average temperature of this area is $17^{\circ} \mathrm{C}$, and the temperature difference between winter and summer is large. The survey area is mostly characterized by southeast wind and east wind throughout the year, with an average annual wind speed of $2.8 \mathrm{~m} / \mathrm{s}$. The annual average amount of light time is $2012.4 \mathrm{~h}$. The average annual precipitation is $1300 \mathrm{~mm}$. The annual average evaporation in this area is $1611.4 \mathrm{~mm}$, and the maximum monthly evaporation occurs from June to August. The meteorological factors such as temperature, wind speed, light time, rainfall, evaporation, and other meteorological factors show no considerable differences in these sampling points. The basic information of these points is shown in Table 1. The time gaps of these areas from completion to sampling are more than three years, which provides value for sampling survey. The bank stabilization sampling points are scattered along the riverbank.
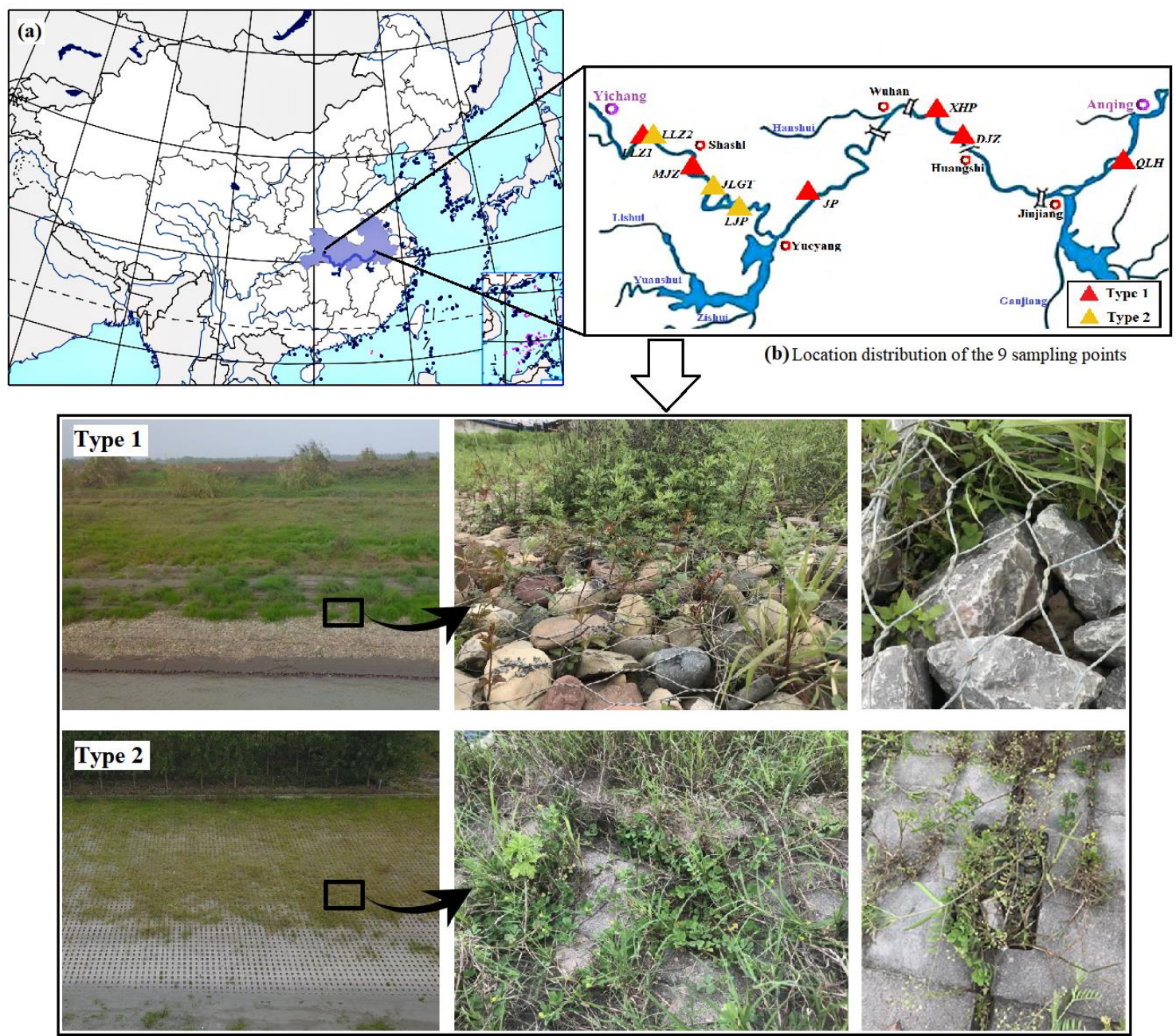

(c) Site photos of the Steel mesh gabion bank stabilization (Type 1) and Chain-type bricks bank stabilization (Type 2)

Figure 1. The site of the study area along the Yichang-Anqing of the middle and lower reaches of the Yangtze River. Three pictures show the study area. (a) The study area in Hubei and Anhui province; (b) schematic diagram of the location distribution of sampling points; (c) site photos of the two types of bank stabilization structures. 
Table 1. Basic information of sampling points.

\begin{tabular}{|c|c|c|c|c|c|}
\hline Sites & Type & $\begin{array}{c}\text { Construction } \\
\text { Work Time }\end{array}$ & $\begin{array}{l}\text { Sampling Time } \\
\text { before the Flood }\end{array}$ & $\begin{array}{l}\text { Sampling Time } \\
\text { after the Flood }\end{array}$ & Pioneer Vegetation \\
\hline LLZ1 & 1 & 2014.06 & 2019.4.18 & 2019.10.09 & Cynodon dactylon \\
\hline LLZ2 & 2 & 2014.06 & 2019.4.18 & 2019.10.09 & Cynodon dactylon \\
\hline MJZ & 1 & 2012.06 & 2019.4.19 & 2019.10.10 & Natural restoration \\
\hline JLGT & 2 & 2012.10 & 2019.4.19 & 2019.10.10 & Cynodon dactylon \\
\hline LJP & 2 & 2015.03 & 2019.4.18 & 2019.10.12 & Cynodon dactylon \\
\hline $\mathrm{JP}$ & 1 & 2013.03 & 2019.4.17 & 2019.10.13 & $\begin{array}{l}\text { Cynodon dactylon, } \\
\text { Cynodon dactylon, }\end{array}$ \\
\hline XHP & 1 & 2016.01 & 2019.3.28 & 2019.09.26 & $\begin{array}{l}\text { Phragmites communis, } \\
\text { Hemarthria altissima }\end{array}$ \\
\hline DJZ & 1 & 2011.08 & 2019.3.29 & 2019.09.27 & Cynodon dactylon, Festuca elata \\
\hline QLH & 1 & 2014.05 & 2019.4.27 & 2019.09.28 & $\begin{array}{l}\text { Cynodon dactylon, } \\
\text { Hemarthria altissima }\end{array}$ \\
\hline
\end{tabular}

\subsection{Introduction of Bank Stabilization Structures}

Type 1: Steel mesh gabion bank stabilization

The steel mesh gabion bank stabilization structure is composed of wire baskets filled with rocks (Figure 1c). The steel wire of wire baskets under anti-corrosion treatment is with the properties of corrosion resistance, high strength, and good flexibility. This structure has a rough surface, and the sediment in the gabion is easily deposited. At the initial stage of bank stabilization, natural soil with a thickness of approximately $3-5 \mathrm{~cm}$ is usually laid in the steel mesh grid of bank stabilization. Grass seeds are sown to carry out the slope structure greening, using vegetation to protect the soil, reducing the probability of soil erosion in the ecological bank stabilization area [21].

Type 2: Chain-type bricks bank stabilization

Chain-type bricks bank stabilization is composed of slope bedding and concrete prefabricated slope bricks with a unique interlocking shape. Each brick and its adjacent six bricks form an excellent interlocking state (Figure 1c). At the same time, the interstices of interlocking bricks are filled with graded crushed stone. Holes in the middle make the bricks porous, permeable, and breathable. Natural soil is paved in the holes and vegetation is planted [22].

\subsection{Methods}

\subsubsection{Field Investigation}

At the sampling points, parallel to the riparian line, the riverbank slopes were divided into three zones according to the elevation of low water platform and the top, namely, the upper, middle, and the lower parts of the bank stabilization structures. A global positioning system named i 90 inertial navigation Real-time kinematic (RTK) was used to locate and determine the elevation of the sampling points. Three vegetation survey quadrants were randomly set up in each sampling zone (Figure 2). Herbaceous quadrants were $1 \mathrm{~m} \times 1 \mathrm{~m}$ and shrub quadrants were $5 \mathrm{~m} \times 5 \mathrm{~m}$. The topsoil samples $(0-20 \mathrm{~cm})$ were pierced and collected from the root zone in the vegetation survey sample quadrants using a soil drill, and those of the same sampling zones were pooled together to form one composite sample [23]. Sampling was carried out before and after the flood season. Six substrate samples were collected before and after the flood season for each site. A total of 54 substrate samples were taken. The specific sampling time of each sampling point is shown in Table 1. 

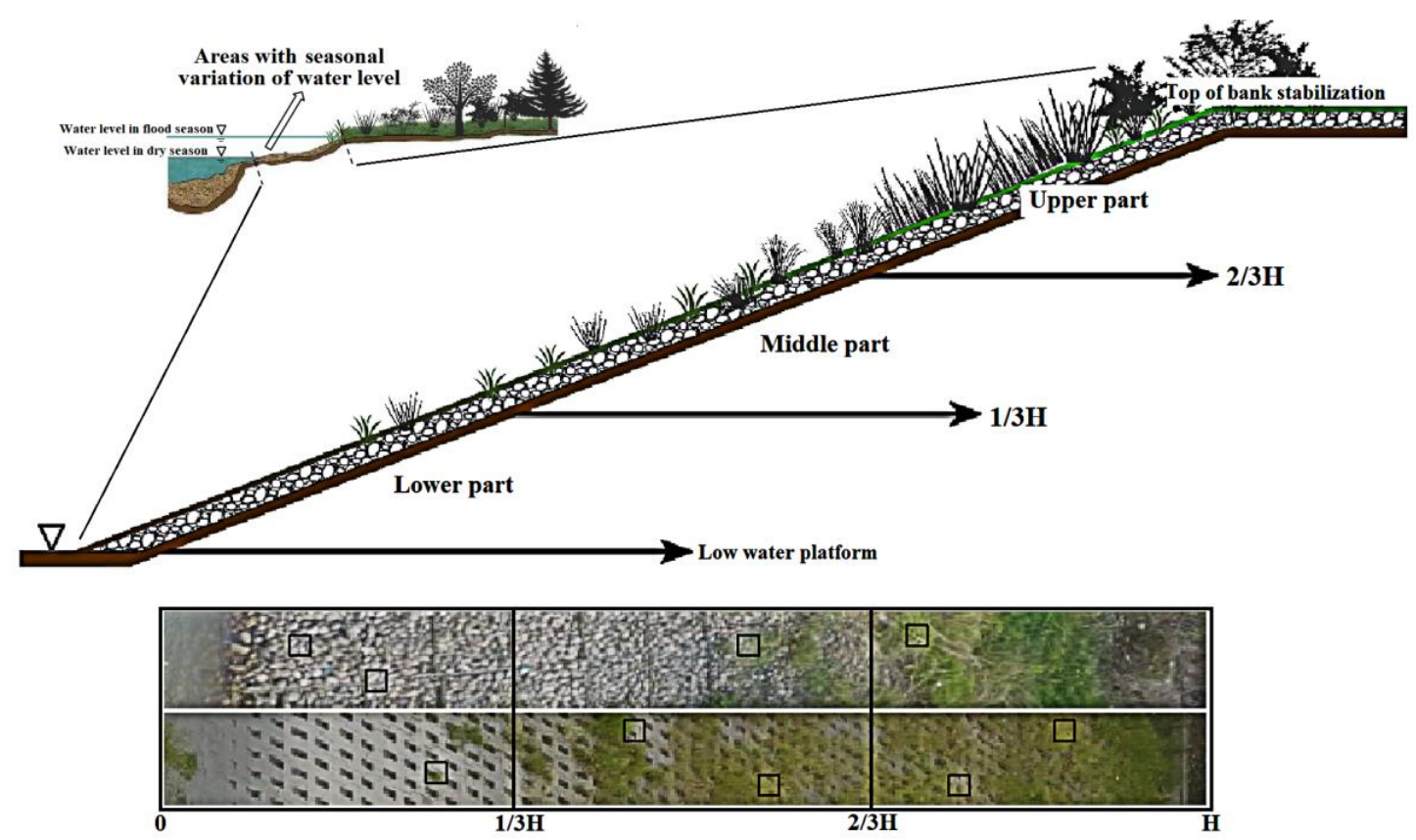

Figure 2. Schematic diagram of sampling zone division of bank stabilization.

2.3.2. Calculation of Vegetation Succession Characteristic Index and Determination of Physical and Selected Chemical Properties of Substrate

Four biotic indices were selected to reflect the succession characteristics, including cover (Cov), average height (Height), Shannon-Wiener diversity index (S-W), and Margalef richness index (Mar). The soil samples brought back to the laboratory were subjected to pre-treatment, such as drying and grinding. The substrate samples were divided into 2 parts, one part was configured into the solution with appropriate concentration using Microtrac S3500 (laser particle size analyzer) to carry out the measurement of sediment particle size gradation and the other part was used to measure $\mathrm{pH}$ and the content of each nutrient [23].

\subsubsection{Data Analysis}

According to the annual water level process of the Middle and lower Yangtze River. We counted the statistical results of average annual duration of submergence on each slope zones (Table 2). Correlation analysis and Redundancy analysis were carried out by using vegetation and substrate data before the flood season. Pearson correlation analysis was carried out between relative elevation and soil nutrients using SPSS 22.

Table 2. The statistical results of average annual duration of submergence on each slope zones.

\begin{tabular}{|c|c|c|c|c|c|c|c|}
\hline \multirow{2}{*}{ Sites } & \multirow{2}{*}{$\begin{array}{c}\text { Elevation of } \\
\text { the Low Water } \\
\text { Platform }\end{array}$} & \multicolumn{3}{|c|}{$\begin{array}{l}\text { Range of Sampling Zones } \\
\text { Relative to the Low Water Platform (m) }\end{array}$} & \multicolumn{3}{|c|}{$\begin{array}{l}\text { Average Annual Duration of } \\
\text { Submergence (Day) }\end{array}$} \\
\hline & & Upper Part & Middle Part & Lower Part & Upper Part & Middle Part & Lower Part \\
\hline LLZ1 & 31.40 & $>4.60$ & $2.30-4.60$ & $0-2.30$ & 27 & 67 & 137 \\
\hline LLZ2 & 31.40 & $>4.60$ & $2.30-4.60$ & $0-2.30$ & 27 & 67 & 137 \\
\hline MJZ & 29.60 & $>5.04$ & $2.52-5.04$ & $0-2.52$ & 32 & 95 & 159 \\
\hline JLGT & 30.60 & $>4.80$ & $2.40-4.80$ & $0-2.40$ & 24 & 61 & 122 \\
\hline LJP & 26.51 & $>6.00$ & $3.00-6.00$ & $0-3.00$ & 33 & 101 & 173 \\
\hline $\mathrm{JP}$ & 19.04 & $>8.00$ & $4.00-8.00$ & $0-4.00$ & 47 & 110 & 184 \\
\hline $\mathrm{XHP}$ & 12.60 & $>8.00$ & $4.00-8.00$ & $0-4.00$ & 47 & 110 & 184 \\
\hline DJZ & 11.06 & $>8.46$ & $4.23-8.46$ & $0-4.23$ & 46 & 116 & 184 \\
\hline QLH & 5.69 & $>6.64$ & $3.32-6.64$ & $0-3.32$ & 94 & 150 & 184 \\
\hline
\end{tabular}

The Yellow Sea Height Datum is adopted to the elevation of low water platform. 
CANOCO is a software package for multivariate data analysis and visualization, with an emphasis on dimension reduction (ordination), regression analysis, and the combination of the two, constrained ordination. It can accurately explain the relationship between vegetation and environmental factors and between environmental factors [24]. Four biotic indices and 17 environmental impact factors were found such as average annual duration of submergence (FT); time gap between the completion of bank stabilization and sampling before flood (CT); height of the sampling area relative to the low water platform (RH); \% Clay (Clay); \% Silt (Silt); \% Sand (Sand); median diameter (MD); maximum grain size (MGS); heterogeneous coefficient (HC); $\mathrm{pH}$; organic matter (OM); total nitrogen (TN); total phosphorus (TP); total potassium (TK); available nitrogen (AN); available phosphorus (AP); and available potassium (AK). These factors were selected based on the field observation survey sampling and experimental measurement data. The partial Monte-Carlo permutation tests of CANOCO 5.0 was used to evaluate the contribution of environmental impact factor to the biotic indices. According to the test results, the spatial distribution and diversity of vegetation and environmental factors of significant contribution were analyzed using Redundancy Analysis (RDA) $[23,25]$.

\section{Results}

\subsection{Vegetation}

A total of 77 plant species were collected from the nine sampling points. Among these, Gramineae had the largest number of species, with 15 species accounting for $19.48 \%$ of the total, 11 species of Compositae, 6 species of Leguminosae, 5 species of Labiatae, and 4 species of Polygonaceae. On the basis of the Flora of China, 36 species of annual or biennial herbaceous plants account for $46.75 \%$ of the total, 34 species of perennial herbs, 3 species of lianas, and 4 species of arbors were identified. Judging from the survey results of dominant species, whether in the upper, middle, or lower part of the slope, before the flood season, vegetation on the slope was dominated by annual or biennial herbaceous plants such as Vicia sativa, Trigonotis peduncularis, and Leonurus japonicus. After a flood season, a large number of annual or biennial herbaceous plants on the slope disappeared, and slope vegetation evolved into a dominant species dominated by perennial herbs such as Cynodon dactylon, Paspalum paspaloides, and Phragmites communis. Field observations revealed that wild peas, which had an extremely prominent dominance in the middle and lower part of the bank stabilization before the flood season, disappeared in a large area after the flood season. Wild peas' dominance decreased significantly, and the species appeared to be dry and apoptotic. The annual or biennial herbaceous plants basically disappeared and became hard to trace.

\subsubsection{Cover}

Before the flood season, the vegetation cover of the two types gradually decreased from the top to the bottom (Figure 3). The cover of the sampling zone in different elevation regions had little difference. After the flood season, the vertical spatial distribution regularity of cover was the same as before the flood season. However, the vegetation cover of the two types showed different degrees of reduction, especially on the lower part. The cover of Type 1 decreased from $62.78 \%$ to $27.33 \%$, the cover of Type 2 decreased from $74.67 \%$ to $11.33 \%$, and the cover under Type 2 drastically decreased. 


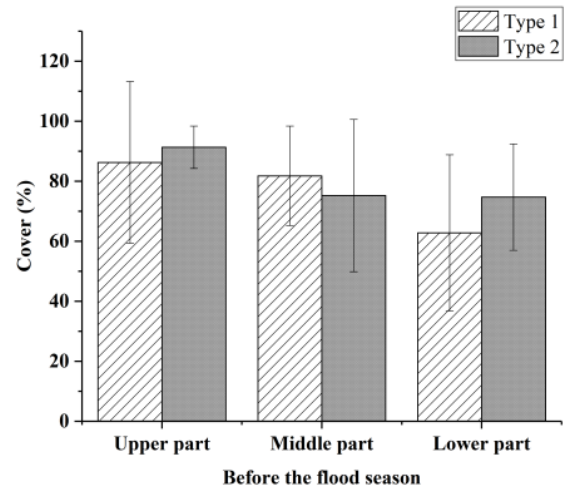

(a)

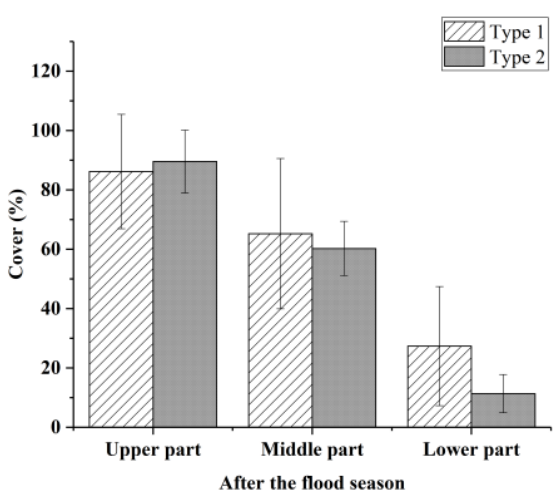

(b)

Figure 3. Vegetation cover of two types: (a) Before the flood season; (b) after the flood season.

\subsubsection{Average Height}

Before the flood season, the average height of the two types showed a gradually decreasing trend from top to the bottom (Figure 4). The average height in different elevation areas of the same type showed no considerable differences. The average height of Type 1 was higher than that of Type 2 . After a flood season, the average height in the middle of Type 1 was significantly higher than that of the same location before the flood and it was clearly greater than those of the other parts. The average height on the upper part of Type 2 was significantly higher than before the flood season, and the average height on the lower part significantly decreased. The vertical spatial distribution regularity of the average height of Type 2 was the same as before the flood.

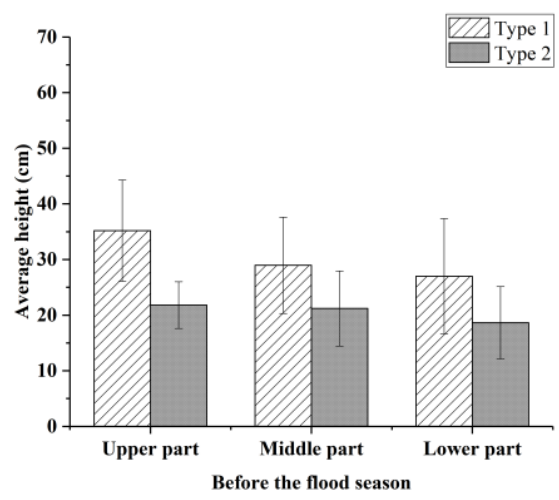

(a)

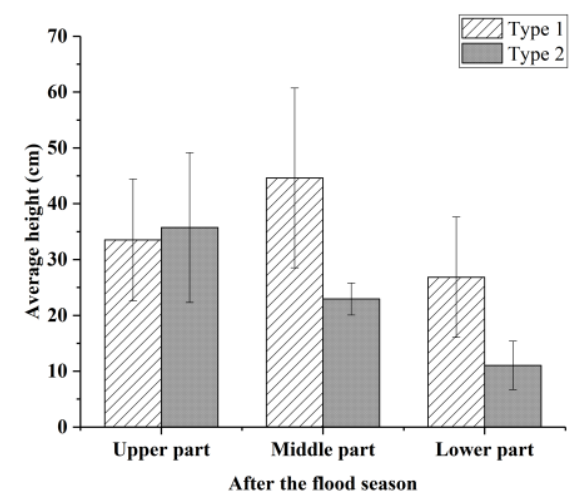

(b)

Figure 4. Average height of two types: (a) Before the flood season; (b) after the flood season.

\subsubsection{Species Diversity Index}

Before the flood season, the Shannon-Wiener and Margalef indices of two types were not much different on the whole. The differences between the indices of the different parts of the same type were not obvious (Figure 5). On the lower area, the indices of the two types decreased to different degrees after the flood season compared with the values before the flood. The degree of decrease from top to bottom increased. The reduction degree of the two major indices of Type 2 was greater than that of Type 1. 


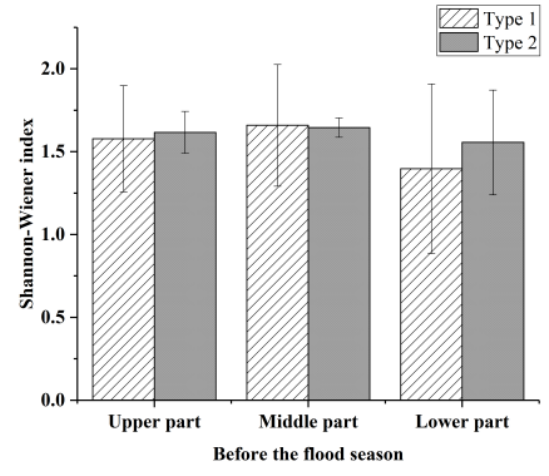

(a)

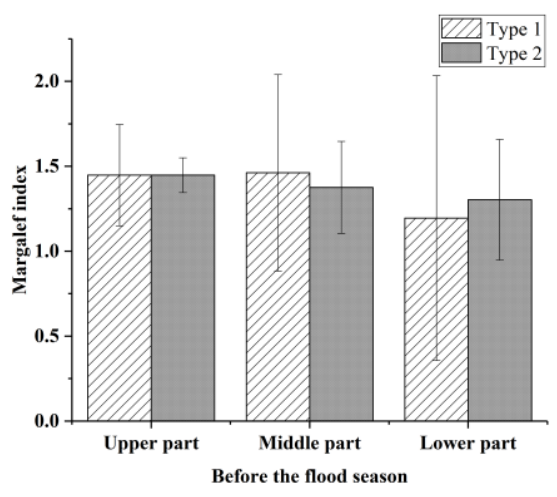

(c)

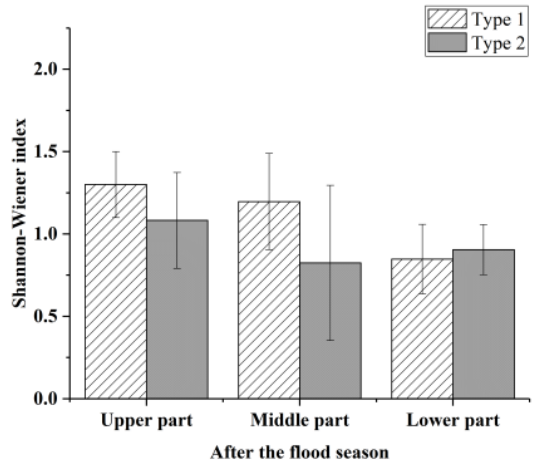

(b)

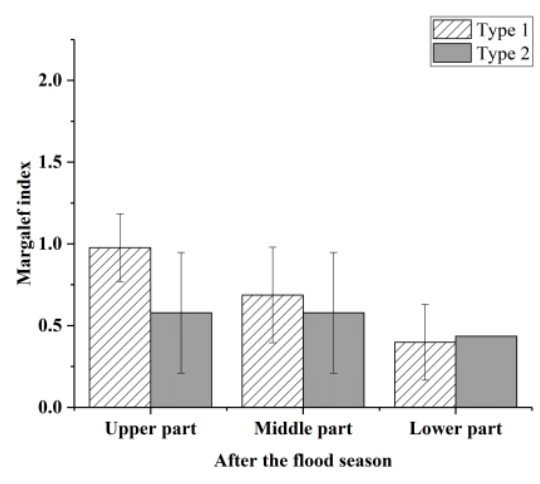

(d)

Figure 5. Species diversity index of two types: (a) Shannon-Wiener indices before the flood season; (b) Shannon-Wiener indices after the flood season; (c) Margalef indices before the flood season; (d) Margalef index after the flood season.

\subsection{Substrate}

\subsubsection{Substrate Composition}

Particle size analysis of nine substrate samples before the flood season shows that the main components of the substrate were silt and sand. The average proportion of sand and gravel was 58.55\%, that of silt was $38.61 \%$, and that of clay was $2.84 \%$. Several samples had almost no clay component, and the proportion of clay was close to 0 .

\subsubsection{Substrate Nutrients}

Figure 6 shows the $\mathrm{pH}$ distribution and the average value of each nutrient content in the substrate of each sampling area of the two types before the flood season. The $\mathrm{pH}$ and nutrient content in the substrate had no obvious regularity from the top to the bottom of the two types, while for two types, except for several parts, the nutrient content of Type 1 was richer than that of Type 2. The correlation between soil nutrients and relative height was analyzed (Table 3). Organic matter and total nitrogen were positively related $(p<0.05)$ and available potassium significantly positively $(p<0.01)$ correlated with the relative height of sampling points, $\mathrm{pH}$ was extremely and significantly negatively correlated with organic matter, total nitrogen, total phosphorus, total potassium, available phosphorus, and available potassium $(p<0.01)$. Organic matter was significantly positively correlated with total nitrogen, total potassium, and available nitrogen $(p<0.01)$. 


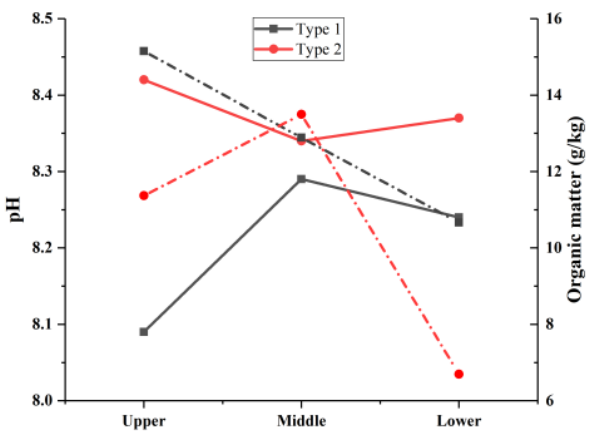

(a)

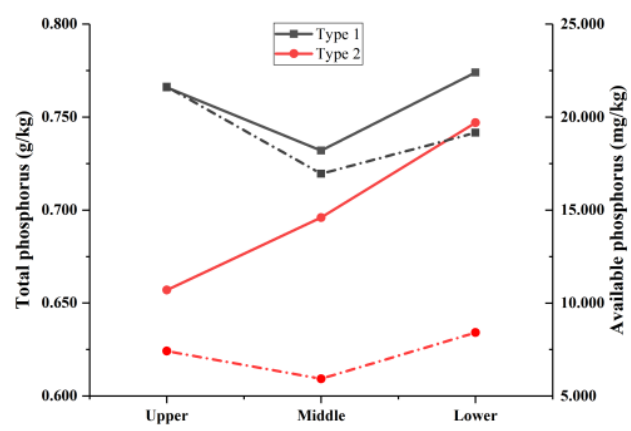

(c)

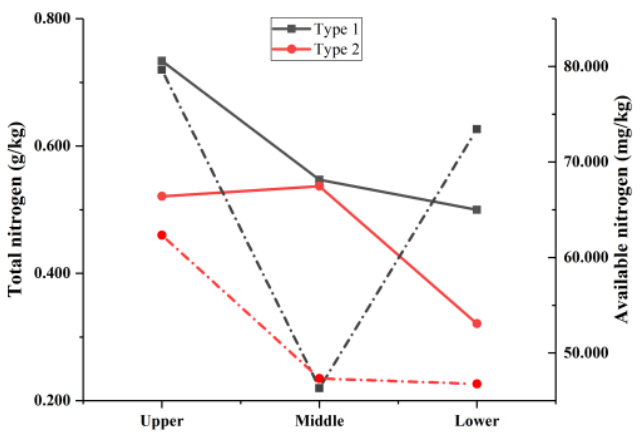

(b)

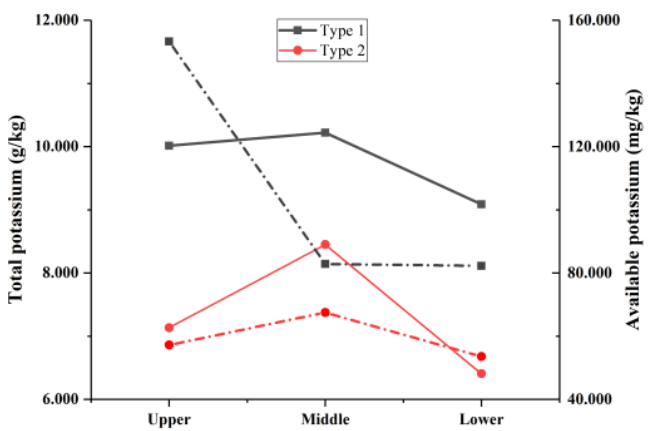

(d)

Figure 6. Distribution of $\mathrm{pH}$ and nutrients in different parts of the two types. The solid line in the figure represents the physical quantity of the left axis, the dotted line represents the physical quantity of the right axis, and the same color represents the same bank stabilization type: (a) $\mathrm{pH}$ and organic matter; (b) total nitrogen and available nitrogen; (c) total phosphorus and available phosphorus; (d) total potassium and available potassium.

Table 3. Correlation between soil nutrients.

\begin{tabular}{|c|c|c|c|c|c|c|c|c|}
\hline & RH & $\mathrm{pH}$ & OM & TN & TP & TK & AN & AP \\
\hline RH & 1 & & & & & & & \\
\hline $\mathrm{pH}$ & -0.234 & 1 & & & & & & \\
\hline OM & $0.419 *$ & $-0.651^{* *}$ & 1 & & & & & \\
\hline $\mathrm{TN}$ & 0.425 * & $-0.673^{* *}$ & $0.947^{* *}$ & 1 & & & & \\
\hline $\mathbf{T P}$ & -0.069 & $-0.467 *$ & 0.434 * & $0.489 *$ & 1 & & & \\
\hline TK & 0.214 & $-0.652^{* *}$ & $0.863 * *$ & $0.865^{* *}$ & 0.418 * & 1 & & \\
\hline AN & 0.014 & -0.373 & 0.563 ** & $0.629 * *$ & 0.299 & $0.567^{* *}$ & 1 & \\
\hline $\mathbf{A P}$ & 0.238 & $-0.620^{* *}$ & 0.491 * & $0.613^{* *}$ & $0.497^{*}$ & $0.581^{* *}$ & 0.422 * & 1 \\
\hline AK & $0.595^{* *}$ & $-0.474 *$ & 0.458 * & $0.512^{* *}$ & 0.294 & 0.315 & 0.334 & $0.537^{* *}$ \\
\hline
\end{tabular}

** Correlation is significant when the confidence (double test) is 0.01 . ${ }^{*}$ Correlation is significant when the confidence (double test) is 0.05 .

\subsection{Effects of Environmental Impact Factors on Biotic Indices}

Figure 7 shows the results of analysis between four biotic indices and 17 environmental impact factors using RDA. For Type 1, 88.86\% of the information in RDA was explained by axis 1 and $5.52 \%$ was explained by axis 2 . The correlation coefficients between vegetation and environment in the first two axes were quite high, explaining $94.38 \%$ of the total variance of the vegetation-environment 
relationship. For Type 2, axis 1 expressed $92.88 \%$ of the information and axis 2 expressed $7.01 \%$, explaining $99.89 \%$ of the total variance of the vegetation-environment relationship. Each circle in the plot denotes individual samples. The smaller the angle between the arrow of environmental impact factor and the arrow of biotic index, the stronger the correlation becomes. The longer the arrow of environmental impact factor is projected on the arrow of biotic index, the greater the effect on vegetation becomes. For Type 1: The RDA results show that RH and FT are significantly correlated with the height, while $\mathrm{CT}, \mathrm{pH}$, and Clay are positively correlated with the diversity and richness of vegetation. Cover has a significant negative correlation with the MD. For Type 2: Cover has a significant negative correlation with MD and MGS. Species diversity has a significant positive correlation with OM, TN, TK, and AK.

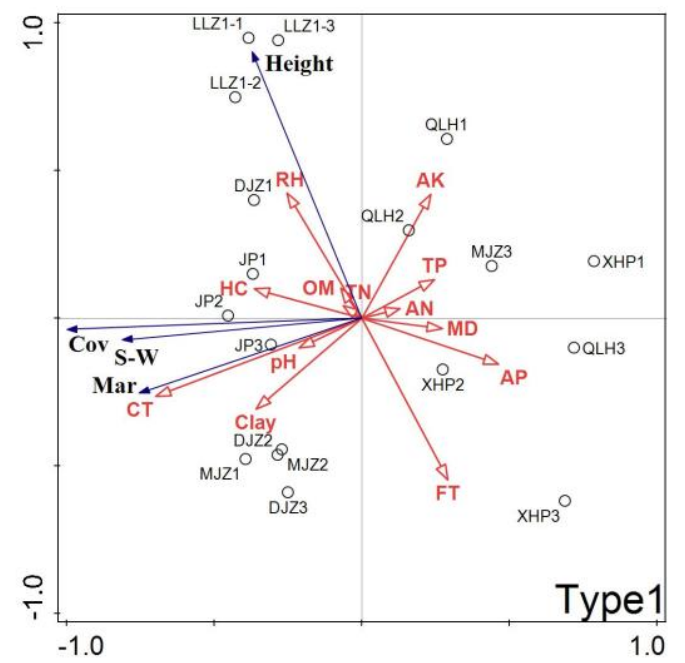

(a)

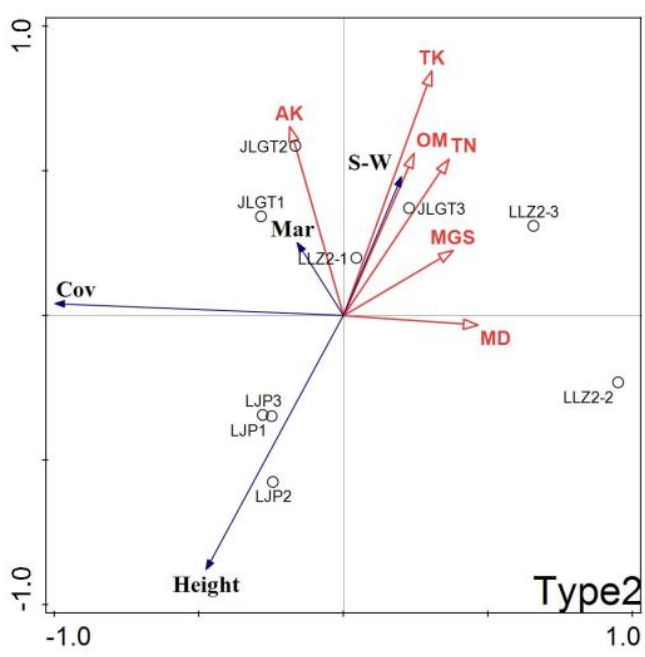

(b)

Figure 7. Redundancy analysis (RDA) Biplot showing effect of environmental factors on biotic indices: (a) Type 1; (b) Type 2. Each circle in the plot denotes individual samples. The black arrows represent biotic indices, and the red arrows represent environmental impact factors of great contribution. The abbreviations defined in the Figure 7 are as follows: Cover (Cov); average height of vegetation (Height); Shannon-Wiener index (S-W); Margalef Index (Mar); average annual duration of submergence (FT); time gap between the completion of bank stabilization and sampling before flood (CT); height of the sampling area relative to the low water platform (RH); \% Clay (Clay); \% Silt (Silt); \% Sand (Sand); median diameter (MD); maximum grain size (MGS); heterogeneous coefficient (HC); $\mathrm{pH}$; organic matter (OM); total nitrogen (TN); total phosphorus (TP); total potassium (TK); available nitrogen (AN); available phosphorus (AP); and available potassium (AK).

\section{Discussion}

\subsection{Comparison of Two Types on Vegetation and Substrate}

In this investigation, the vegetation and substrate characteristics between the two types were compared and analyzed on the time scale and vertical gradient.

On the time scale, single or two mixed pioneer vegetation were planted or sown during the construction of bank stabilization. Vegetation types of the nine ecological bank stabilization zones were developed communities that were mainly composed with Gramineae and Compositae and most of them were relatively short herbaceous plants. This result was similar to the plant communities in water level fluctuating zones of reservoir with the anti-natural rhythm water level regulation, which led to the reverse succession and plants to be dominated by annual or biennial herbaceous herbs [26]. Meanwhile, it was similar as that of other zones with periodic flood disturbances in the same reach. Thus, to accelerate the succession of vegetation to form a more stable community, the research of 
suitable mixtures of pioneer vegetation seeds has considerable value, which was the same conclusion as Giupponi et al. [18]. No matter what type, in terms of changes in the year, the species was dominated by annual or biennial plants before the flood season. After a flood season, a large amount of annual or biennial plants on the bank stabilization surface disappeared and perennial herbs became the dominant species. The dominant species of the two types showed similar inter-annual and intra-annual changes.

Nevertheless, comparing the vegetation characteristics, Type 1 was better than Type 2 in overall vegetation restoration and growth. This phenomenon was more consistent with the nutrient distribution in the two types of substrate (Figure 6). The nutrient content of Type 1 was richer than that of Type 2 except several zones. Before the flood season, the vegetation cover and diversity of Type 1 was slightly better than that of Type 2, while vegetation cover and diversity reduction scale of Type 2 in different elevation areas were significantly larger than that of Type 1 after a flood, when slope vegetation was more sensitive to periodic flood disturbance.

In terms of spatial gradient, regardless of the values before or after flood, the higher the relative low-water platform height of the two types, the higher the results on cover, diversity, and richness of vegetation and the better the growth. This scenario was consistent with the field observation (Figure 1c) and the conclusion of Abernethy and Willby [27]. Overall, this phenomenon was consistent with the results of the correlation analysis between nutrients and RH (Table 3), which indicated that RH was the main factor affecting the nutrient distribution on the slope. The higher the sampling points, the less disturbed and easier for the nutrients to stay in the substrate, and thereby the richer the nutrients and the better the vegetation growth. On the lower parts, periodic flood disturbance with the scrubbing effect of waves led to difficulties for nutrients to be stored in the substrate. Throughout the year, accumulation in the upper parts caused a virtuous circle of vegetation succession, and the vegetation community became increasingly stable.

\subsection{Comparison of the Two Types under RDA Results}

Vegetation of ecological bank stabilization plays an important role on the stabilization of the channel-width in the riparian zone ecosystem. The relationship between vegetation composition and its diversity and environmental factors has been widely discussed [28,29]. Specific studies on riparian zones and water-level-fluctuating zones also proved that environmental factors played a key role in affecting the vegetation distribution and composition [23]. The correlation between vegetation and environmental factors has been widely examined, although the latter was simply considered as soil factors that were generally divided into two aspects: Substrate physical and chemical properties [18]. Soil factor has become an indispensable factor in the study of the relationship between vegetation and environment in controlling the distribution of vegetation. Different from previous research, this study not only considered the physical and chemical properties of the soil but also included other environmental factors such as average annual duration of submergence and the time gap between the completion of bank stabilization and sampling before flood. However, in consideration of the substrate physical properties, the emphasis was on the particle size. This result showed several similarities with the selected substrate factors in other works [30]. From Figure 1, the bank stabilization sampling points are scattered along the riverbank and the sites of Type 1 and Type 2 are not in close proximity in. A series of data of these areas before sampling was collected and analyzed. The middle and lower reaches of the Yangtze River is plain river whose drop is small, and sampling points are distributed on both banks of the Yangtze River's mainstream. So, the meteorological factors of these sampling points such as light time, temperature, rainfall, evaporation, wind speed, and other factors have little difference. The influence of the spatial heterogeneity can be ignored. To sum up, the selection of environmental impact factors that have a significant impact on vegetation was shifted to the 17 environmental impact factors in the study.

Comparison of the RDA results of the two types revealed that CT and clay had considerable influence on the richness and diversity of Type 1, while the organic matter and other nutrient contents had little impact. Nevertheless, the latter had a greater impact on the richness and diversity of 
vegetation in Type 2 . The main environmental factors that cause the diversity and richness of the two types were quite different. Comprehensive analysis found that in Type 1, the overall plant cover was better than Type 2. The upper, middle, and lower parts of the bank stabilization structures were basically covered by plants before the flood. Stabilization was vulnerable at the early stage of the project because of the natural earth foundation. With the established vegetation community, root systems bind soils and the riverbank became stronger [4].

For Type 1, because this structure has a rough surface, the deposited division in the gap covers the gap and surface of the structure. During the flood season, material exchange between the substrate and water flow of Type 1 was more frequent Meanwhile, annual or biennial plants retained seeds and waited to grow and develop in the coming year. Substrate with smaller grain size diameters found it easier to retain the seeds of the herbaceous plants left during the flood season. Therefore, the proportion of clay was an important factor affecting vegetation diversity and richness of Type 1. However, the substrates of the riverbanks were periodically reorganized through erosion and deposition due to regular flooding. Some people think that the resilience of plant communities might thus be more influenced by spatial dispersal along rivers and across landscapes than by in situ temporal dispersal in soils [31]. Seeds can also be maintained by annuals and supplemented by inputs from habitats upstream. Thus, apart from spatial dispersal, the temporal seed storage in riparian soils may also play a key role in riparian community dynamics [27].

As for Type 2, the slope chain-type brick blocks the scouring and material exchange of water flow to a certain extent. The interstices of the chain-type bricks can provide moist beds for the seeds of annual or biennial plants. OM is a soil parameter that determines the presence of their decomposed material in the soil [23]. OM produced after vegetation decay is easier to store in the cracks of the chain-type bricks of Type 2. Thus, the OM and other nutrient contents became the main influencing factor of Type 2.

This is a systematic survey on the vegetation and substrate after two types of bank stabilization structures that have been applied in large riverbank areas in the middle and lower reaches of the Yangtze River. Seventeen environmental factors affecting the effect of revetment vegetation restoration were comprehensively considered and selected. The most important factors affecting the two types of bank stabilization were obtained by using RDA, which provided a certain basis for engineering optimization and selection. In this study, the riverbank slopes were divided into three zones equally according to the elevation of low water platform and the top. However, according to the aerial photos after the flood season, it is found that there is a clear and visible boundary paralleling to the riverbank on each slope, which is between the two zones on the slope; that one vegetation grows well and the other vegetation is relatively sparse affected by the periodic fluctuation of water level, wave erosion, soil properties, and other factors. Some studies show that there is a step difference in the number and species of vegetation on the vertical spatial distribution regularity between the two zones [32]. The division basis of elevation zones of bank stabilization can be optimized in the following study. The number of sampling points of Type 2 was less than that of Type 1, and the corresponding regularities need further verification.

\section{Conclusions}

Based on the comprehensive analysis of the survey results, annual or biennial herbaceous plants had clear spatial competitive advantages. The remaining seeds can grow and develop in a large area on the slope before the flood season of the coming year. By comparison, perennial herbs plants with strong tolerance to flood and strong soil-fixation had clear competitive advantages in the long term and can form a stable dominant population in the middle and upper parts after the flood.

The combined results of the correlation analysis and RDA show that vegetation must establish quickly and solidly on riverbanks to give full play to the ecological benefits. For Type 1, the clay content in the substrate was an important factor affecting vegetation cover and diversity. When paving the substrate at the initial stage, particle size gradation of the substrate needed to be reasonably 
adjusted instead of simply and directly laying the local natural soil. For Type 2, the substrate nutrient composition was an important factor affecting vegetation cover and diversity. When selecting suitable pioneer vegetation, nutrient retention can be considered in addition to the flood tolerance.

In general, the capacity of vegetation restoration and resisting periodic flood disturbance of the steel mesh gabion was significantly higher than that of the chain-type bricks bank stabilization. Therefore, steel mesh gabion bank stabilization presented stronger environmental adaptability in channel regulation projects and can be given greater priority when structural stability had been satisfied.

Author Contributions: Data curation, Y.F.; funding acquisition, Z.Y.; investigation, Y.F., Z.Y., M.L., Z.Z., and D.L.; project administration, Z.Y. and M.L.; writing—original draft, Y.F.; writing-review and editing, Z.Z. All authors have read and agreed to the published version of the manuscript.

Funding: This research was supported by the National Natural Science Foundation of China (Grant No. 51879199 and 52020105006) and Science and Technology Department of Hubei Province (Grant No. 2019ACA154).

Acknowledgments: The authors acknowledge the invaluable support from Liu Qi of the Changjiang Waterway Institute of Planning and Design for field investigation and laboratory work from Zou Mingzhe of School of Water Resources and Hydropower Engineering, Wuhan University.

Conflicts of Interest: The authors declare no conflict of interest.

\section{References}

1. Zhang, J.; Peng, B. Study on riparian zone and the restoration and rebuilding of its degraded ecosystem. Acta Ecol. Sin. 2003, 23, 56-63.

2. Feld, C.K.; Birk, S.; Bradley, D.C.; Hering, D.; Kail, J.; Marzin, A.; Melcher, A.; Nemitz, D.; Pedersen, M.L.; Pletterbauer, F.; et al. From natural to degraded rivers and back again: A test of restoration ecology theory and practice. Adv. Ecol. Res. 2011, 44, 119-209.

3. Kenwick, R.A.; Shammin, R.; Sullivan, W.C. Preferences for riparian buffers. Landsc. Urban Plan. 2009, 91, 88-96. [CrossRef]

4. Osman, N.; Barakbah, S.S. The effect of plant succession on slope stability. Ecol. Eng. 2011, 37, $139-147$. [CrossRef]

5. Stromberg, J.C. Restoration of riparian vegetation in the south-western United States: Importance of flow regimes and fluvial dynamism. J. Arid Environ. 2001, 49, 17-34. [CrossRef]

6. Chen, P. Application analysis of ecological slope protection in river training. Eng. Technol. Res. 2020, 5, 277-278.

7. Li, M.; Eddleman, K.E. Biotechnical engineering as an alternative to traditional engineering methods: A biotechnical streambank stabilization design approach. Landsc. Urban Plan. 2002, 60, 225-242. [CrossRef]

8. Wyzga, B. A geomorphologist's criticism of the engineering approach to channelization of Gravel-Bed rivers: Case study of the Raba river. Polish Carpathians. Environ. Manag. 2001, 28, 341-358. [CrossRef]

9. Nakamura, F.; Jitsu, M.; Kameyama, S.; Mizugaki, S. Changes in riparian forests in the Kushiro Mire, Japan, associated with stream channelization. River Res. Appl. 2002, 18, 65-79. [CrossRef]

10. Osugi, T.; Tate, S.; Takemura, K.; Watanabe, W.; Ogura, N.; Kikkawa, J. Ecological research for the restoration and management of rivers and reservoirs in Japan. Landsc. Ecol. Eng. 2007, 3, 159-170. [CrossRef]

11. Breton, V.; Forestier, O.; Guindon, O.; Evette, A. Ecological restoration under pressure from invasive animal species: Use of Salicaceae cuttings in a river bank overrun by coypu. River Res. Appl. 2014, 30, 1002-1012. [CrossRef]

12. Cavaillé, P.; Dommanget, F.; Daumergue, N.; Loucougaray, G.; Spiegelberger, T.; Tabacchi, E.; Evette, A. Biodiversity assessment following a naturality gradient of riverbank protection structures in French prealps rivers. Ecol. Eng. 2013, 53, 23-30. [CrossRef]

13. Tisserant, M.; Janssen, P.; Evette, A.; González, E.; Cavaillé, P.; Poulin, M. Diversity and succession of riparian plant communities along riverbanks bioengineered for erosion control: A case study in the foothills of the Alps and the Jura Mountains. Ecol. Eng. 2020, 152, 105880. [CrossRef]

14. Cavaillé, P.; Ducasse, L.; Breton, V.; Dommanget, F.; Tabacchi, E.; Evette, A. Functional and taxonomic plant diversity for riverbank protection works: Bioengineering techniques close to natural banks and beyond hard engineering. J. Environ. Manag. 2015, 151, 65-75. [CrossRef] [PubMed] 
15. Sudduth, E.B.; Meyer, J.L. Effects of bioengineered streambank stabilization on bank habitat and macroinvertebrates in urban streams. Environ. Manag. 2006, 38, 218-226. [CrossRef]

16. Li, X.; Zhang, L.; Zhang, Z. Soil bioengineering and the ecological restoration of riverbanks at the Airport Town, Shanghai, China. Ecol. Eng. 2006, 26, 304-314. [CrossRef]

17. Cheng, L.; Deng, H.; He, S.; Gu, L.; Qu, H. Distribution patterns and diversity of plant communities in fluctuating areas of Chongqing section of Yangtze river. Chin. J. Ecol. 2019, 38, 3626-3634.

18. Giupponi, L.; Borgonovo, G.; Giorgi, A.; Bischetti, G.B. How to renew soil bioengineering for slope stabilization: Some proposals. Landsc. Ecol. Eng. 2019, 15, 37-50. [CrossRef]

19. Jankauskas, B.; Jankauskienè, G.; Fullen, M.A.; Booth, C.A. The Effects of Biogeotextiles on the Stabilization of Roadside Slopes in Lithuania. Balt. J. Road Bridge Eng. 2008, 3, 175-180. [CrossRef]

20. Furey, P.; Nordin, R.; Mazumder, A. Water Level Drawdown Affects Physical and Biogeochemical Properties of Littoral Sediments of a Reservoir and a Natural Lake. Lake Reserv. Manag. 2004, 20, 280-295. [CrossRef]

21. Zhang, G.; Zhang, J.; Wang, Y.; Shao, Y. Preliminary study on eco-slope protection with stone cage under river scouring. Hydro-Sci. Eng. 2018, 112-119.

22. Tong, D.; Li, S.; Song, X.; Qiu, X. Application of Articulated Ecological Revetment Block in Water Environment Revetment Project. Yellow River 2012, 34, 12-13.

23. Yousaf, A.; Shabbir, R.; Jabeen, A.; Erum, S.; Ahmad, S.S. Linkage between herbaceous vegetation and soil characteristics along rawal dam islamabad. J. Soil Sci. Plant Nutr. 2016, 16, 88-100. [CrossRef]

24. Zhang, L.; Su, Z.; Chen, B. Altitudinal Patterns of Species Diversity in the Montane Forest Communities: A Review. J. Mt. Sci. Engl. 2005, 23, 736-743.

25. Zhang, J.; Zheng, B.; Liu, L.; Wang, L.; Huang, M.; Wu, G. Seasonal variation of phytoplankton in the DaNing River and its relationships with environmental factors after impounding of the Three Gorges Reservoir: A four-year study. Proc. Environ. Sci. 2010, 2, 1479-1490. [CrossRef]

26. Li, S.; Deng, Y.; Shi, F.; Hu, M.; Pang, B.; Wang, C.; Li, K.; Chen, M.; Peng, W.; Qu, X.; et al. Research progress of water-level-flucutation zones. Wetland Sci. 2019, 17, 689-696.

27. Abernethy, V.J.; Willby, N.J. Changes along a disturbance gradient in the density and composition of propagule banks in floodplain aquatic habitats. Plant Ecol. 1999, 140, 177-190. [CrossRef]

28. Dyakov, N.R. Gradient analysis of vegetation on the south slope of Vitosha mountain, Southwest Bulgaria. Appl. Ecol. Environ. Res. 2014, 12, 1003-1025. [CrossRef]

29. Ma, T.; Deng, X.; Chen, L.; Xiang, W. The soil properties and their effects on plant diversity in different degrees of rocky desertification. Sci. Total Environ. 2020, 736, 139667. [CrossRef]

30. Bourgeois, B.; Boutin, C.; Vanasse, A.; Poulin, M. Divergence between riparian seed banks and standing vegetation increases along successional trajectories. J. Veg. Sci. 2017, 28, 787-797. [CrossRef]

31. Nilsson, C.; Gardfjell, M.; Grelsson, G. Importance of hydrochory in structuring plant communities along rivers. Botany 1991, 69, 2631-2633. [CrossRef]

32. Zhang, W.; Zhang, Y. The green-to-yellow zone phenomenon and its application on ecological revetment in the middle and lower reaches of Yangtze River. China Harb. Eng. 2018, 38, 22-27.

(C) 2020 by the authors. Licensee MDPI, Basel, Switzerland. This article is an open access article distributed under the terms and conditions of the Creative Commons Attribution (CC BY) license (http://creativecommons.org/licenses/by/4.0/). 